\title{
Zonal management of multi-purpose use of water from arsenic-affected aquifers by using a multi-variable indicator kriging approach
}

\author{
Jin-Jing Lee ${ }^{a}$, Chen-Wuing Liu ${ }^{a, *}$, Cheng-Shin Jang ${ }^{b}$, Ching-Ping Liang ${ }^{a, c}$
}

\author{
a Department of Bioenvironmental Systems Engineering, National Taiwan University, 1, Roosevelt Road, \\ Section 4, Taipei 106, Taiwan, ROC \\ ${ }^{b}$ Department of Leisure and Recreation Management, Kainan University, Luzhu, Taoyuan 338, Taiwan, ROC \\ c Department of Environmental Engineering and Science, Fooyin University, Kaoshiung 831, Taiwan, ROC
}

Received 10 March 2008; received in revised form 2 July 2008; accepted 2 July 2008

\section{KEYWORDS \\ Multiple-variable indicator kriging; Multi-purpose; Groundwater quality; Uncertainty; Hazard}

\begin{abstract}
Summary This work presented a probability map of groundwater resources for multi-purpose uses (irrigation, aquaculture and drinking water) of arsenic (As)-affected aquifers in the Lanyang Plain, northeastern Taiwan. The assessment was based on As and other several compounds and factors that adversely affect water-quality. Multiple-variable indicator kriging (MVIK) was adopted to evaluate numerous hydrochemical parameters for the three water-quality standards in Taiwan. Hydrochemical parameters of groundwater were classified into four main hazard categories - saline hazard, nitrogen hazard, As hazard and $\mathrm{Fe}-\mathrm{Mn}$ hazard. Safe and potentially hazardous groundwater regions for multi-purpose use were delineated according to estimated probabilities by using MVIK. Analytical results for MVIK critical probability of $>0.5$ demonstrate that the proximal-fan, partial central distalfan and mid-fan, and northern distal-fan aquifers complying with most water-quality standards are optimal zones for extracting safe groundwater. Notably, the deep aquifer has a high hazard rating and is less safe than the shallow aquifer. The Fe-Mn hazard in Lanyang Plain groundwater presents in most aquifers, and is partially combined with other hazards, such as the nitrogen hazard and the As hazard. A zonal management plan based on safe groundwater use is formulated to help local governments develop groundwater resources in the Lanyang Plain.

(C) 2008 Elsevier B.V. All rights reserved.
\end{abstract}

\footnotetext{
* Corresponding author. Tel.: +88622362 6480; fax: +886223639557.

E-mail address: Icw@gwater.agec.ntu.edu.tw (C.-W. Liu).
} 


\section{Introduction}

Management and effective use of groundwater typically face great challenges, due to the spatial variability of groundwater quality, and the difficulties in satisfying different water-quality standards for various water use sectors demand. Thus, a comprehensive management index of groundwater for multi-purpose use (irrigation, aquaculture and public water supply) is needed. Groundwater naturally contains many ions and can adversely impact on irrigation, aquaculture and drinking water uses. Water-quality is one of the most critical factors in multi-purpose uses for groundwater. For instance, excessive ions in irrigation water may adversely impact the environment. The most common ions presented in groundwater are chloride $\left(\mathrm{Cl}^{-}\right)$and sodium $\left(\mathrm{Na}^{+}\right)$, particularly in coastal regions. Generally, high concentrations of $\mathrm{Cl}^{-}$and $\mathrm{Na}^{+}$in water retard the plants growth (Karaivazoglou et al. 2005; Grieve et al. 2006). Arsenic (As) accounts for various health hazards (Chiou et al., 2001; Lee et al., 2007). When used for irrigation and aquaculture, groundwater with high As contents is toxic to crops and fish and also results in bioaccumulation of As in their organs, which then poses a potential threat to human health (Huq and Naidu, 2005; Liu et al., 2005; Jang et al., 2006). Growth of farm fish and crops is also influenced by high manganese (Mn) levels (van der Vorm and van Diest, 1979; Frías-Espericueta et al., 2003). Although nitrogen compounds in irrigation water facilitate plant growth, excessive nitrogen leaching into groundwater and surface water adversely affect human health (Yang et al., 1998; Màrquez et al., 1998; Lake et al., 2003).

Spatial distributions of groundwater quality are commonly heterogeneous, varying with depths and locations. However, only limit field data can be acquired due to time and cost constraints. Sparsely measured data contain considerable uncertainty. Geostatistics is widely used in modeling spatial variability and distributions of field data with uncertainty. Indicator kriging (IK), which is a frequently employed non-parametric geostatistical method, makes no assumption of variable distributions and a $0-1$ indicator transformation of data is applied to make the predictor robust for outliers. At an unsampled location, the values estimated by IK are probabilities that do not exceed a specific threshold. Indicator kriging has been frequently applied for estimating the soil pollution by specific heavy metals. For example, Juang and Lee (1998), Castrignanò et al. (2000) and van Meirvenne and Goovaerts (2001) utilized IK to estimate the probabilities of heavy metal distributions in fields and to delineate hazardous areas. Liu et al. (2004) and Goovaerts et al. (2005) used IK to assess As pollution in groundwater and mapped the extents of As pollution in aquifers. Saisana et al. (2004) used IK to classify zones polluted with airborne nitrogen dioxide relative to regulatory standards.

Integrating multiple parameters is important for effective assessment and classification of soil and groundwater quality. Smith et al. (1993), Oyedele et al. (1996), Halvorson et al. (1996) and Diodato and Ceccarelli (2004) successfully applied a multiple-variable indicator kriging (MVIK) to determine soil quality in farmed fields. However, few studies have applied MVIK to identify the zonation of multi-pur- pose water uses in groundwater aquifers. Assessing groundwater quality is also required, using multiple parameters (Jurdi et al., 2002). In Taiwan, water-quality standards for irrigation, aquaculture and drinking water utilized different hydrochemical items and concentration standards. Thus, MVIK is applied to assess groundwater quality for multi-purpose use in this study (Xu et al., 2006).

The objective of this work is to evaluate groundwater quality in the aquifers in the Lanyang Plain for multi-purposes using MVIK. Numerous hydrochemical parameters of groundwater quality were partitioned into four main hazard categories - saline hazard, nitrogen hazard, Fe-Mn hazard and As hazard. The extent and safety of potential hazards were delineated according to various estimated probabilities using MVIK. Analytical results may help Taiwanese government administrators establish a sound plans for groundwater development and management in regions with limited water resources. Moreover, this study can be adopted by other countries to manage effectively multipurpose groundwater use worldwide.

\section{Study area}

\section{Study area and hydrogeology}

The Lanyang Plain, which is located in YiLan County in northeastern Taiwan (Fig. 1), is the alluvial fan of the Lanyang River. The area is triangular, bordered by the Pacific Ocean next to the east, Snow Mountains located to the northwest, and Central Mountains located to the southwest. The main river, the Lanyang River, flows through the middle of the area and flows west to east. The area is approximately $400 \mathrm{~km}^{2}$ with each side of triangular region about $30 \mathrm{~km}$ long (Fig. 1). The groundwater flows from west to east. The western sections of the plain near the mountains comprise the main area for groundwater recharge. Natural recharge is the groundwater resource (Peng, 1995). Unconsolidated sediments underlying the alluvial fan contain abundant groundwater and are of the Quaternary age. The plain is partitioned into proximal-fan, mid-fan, and distal-fan areas Chen (2000). According to the core compositions at different depths at the 22 drilling stations in the Lanyang Plain (Taiwan Central Geological Survey, available on <http://www.hydro.meacgs.gov.tw/Rock13.htm>), the hydrogeological setting of the Lanyang Plain is roughly divided into three aquifers (Fig. 2). The Water Resource Agency (WRA) has set up 40 wells with depths of $18.9-233 \mathrm{~m}$ for monitoring the levels and background quality of groundwater, which is sampled and analyzed annually (<http://www.gweb.wra.gov.tw/wrweb/>). Aquifer 1 is 26.1-56.7 $\mathrm{m}$ deep, aquifer 2 is $70.6-139 \mathrm{~m}$ deep, and aquifer 3 is $157.9-233 \mathrm{~m}$ deep (Fig. 2) (Lee et al., 2008).

Due to insufficient surface water, many residents in the Lanyang Plain extract massive amounts of groundwater for irrigation, aquaculture and household use. Many tourism and manufacturing industries recently developed rapidly in these regions, exacerbating problem of insufficient water resources. Reservoirs are typically difficult and costly to construct. Therefore, with limited water resources, groundwater is considered an alternative to surface water. Agriculture, such as paddy and upland fields, is a common land use 


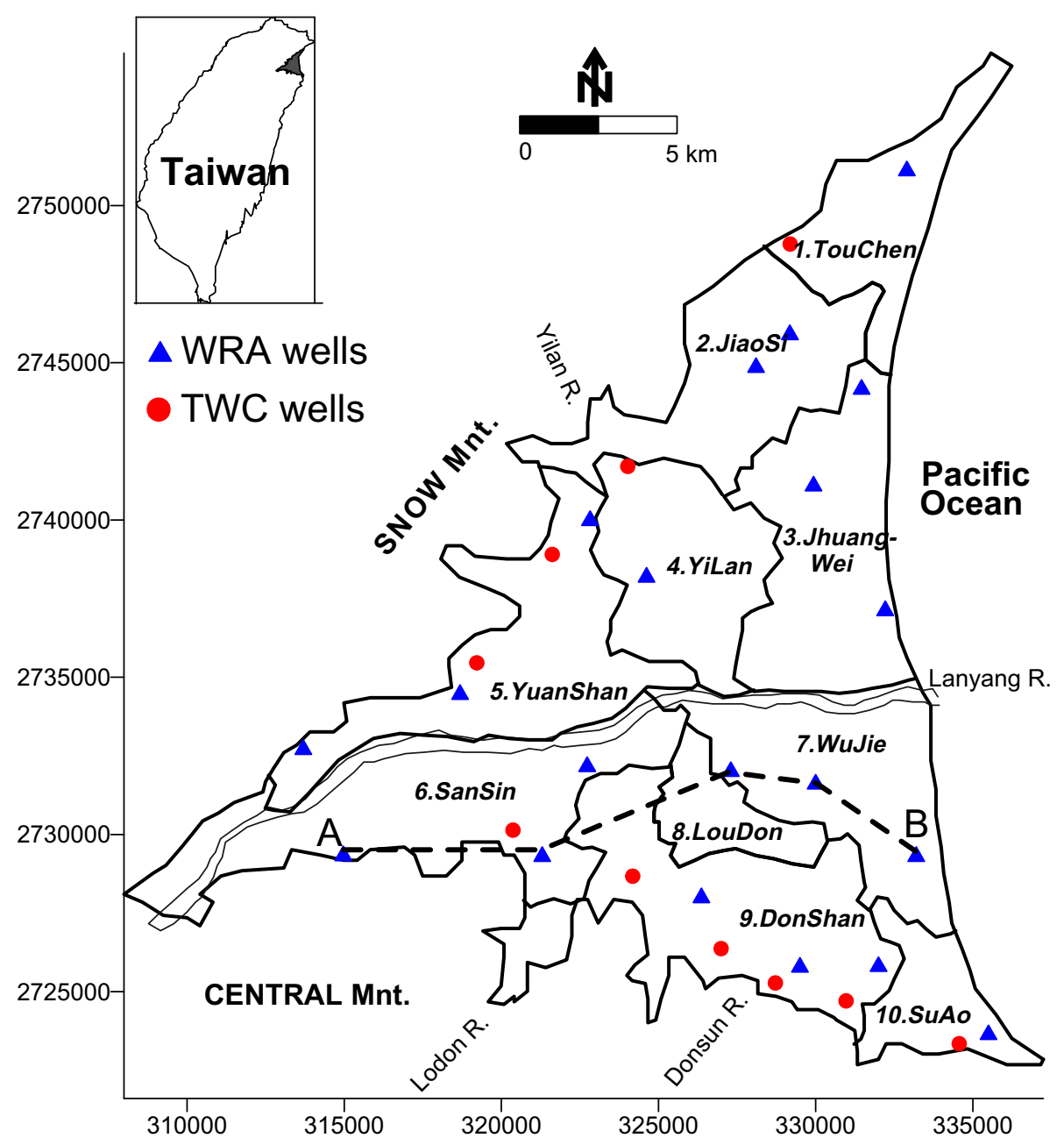

Figure 1 Study area in northern Taiwan.

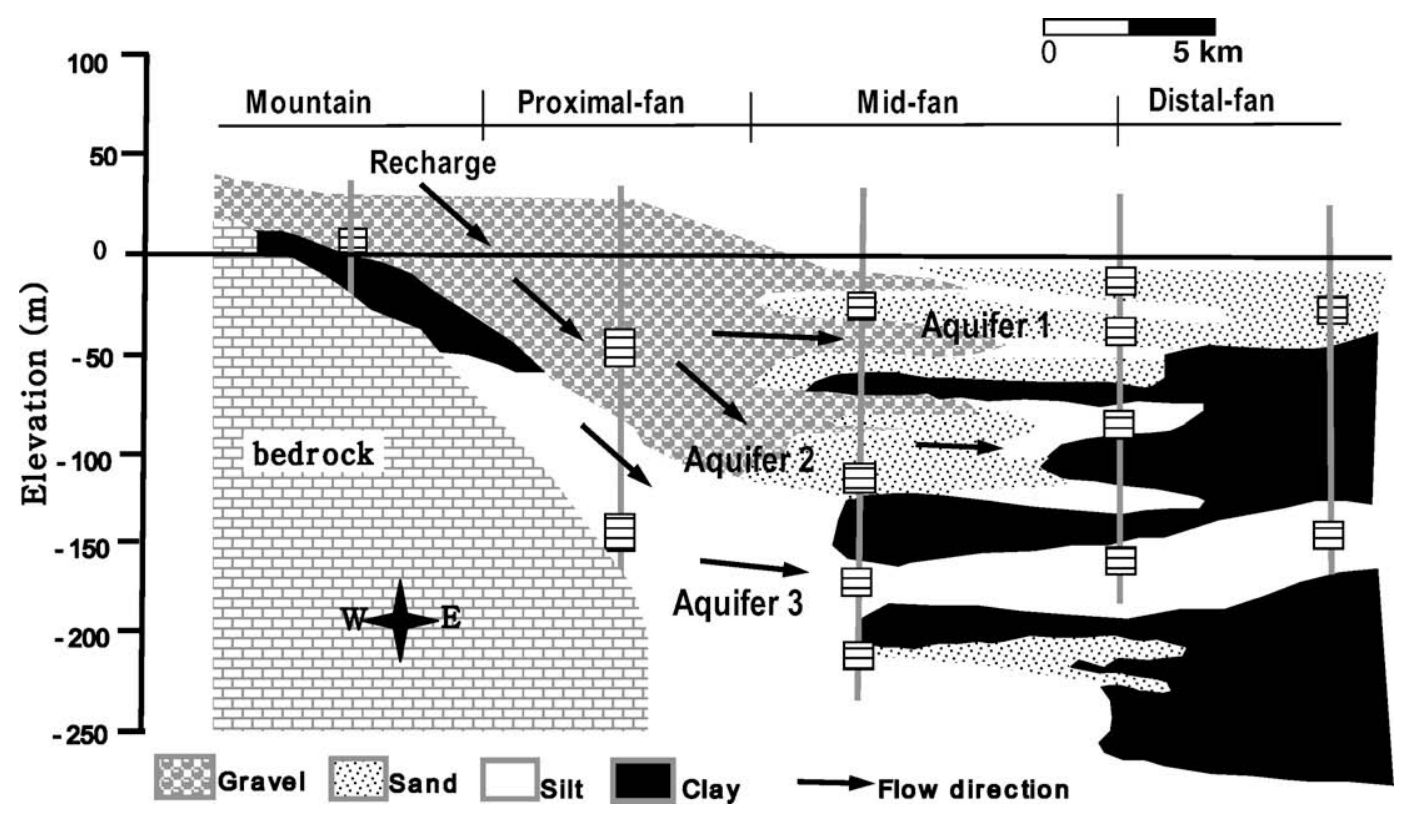

Figure 2 Hydrogeological profile along the A-B section in Figure 1. 
in this region and accounts for about $70 \%$ of total water resources. Aquaculture also accounts for a major proportion of groundwater use in the Don-Shan, Jiao-Si and the coastal regions of the Lanyang plain. Residents of the Lanyang Plain have used shallow wells (depths $<40 \mathrm{~m}$ ) to obtain drinking water since the 1940s (Chiou et al., 2001). Additionally, the Taiwan Water Corporation (TWC) established network wells to monitor changes in groundwater levels and avoid massive extraction of groundwater (Fig. 1). Notably, $60 \%$ of tap water is extracted from groundwater aquifers by the TWC.

\section{Groundwater quality survey and water-quality standards}

A comprehensive survey of groundwater quality, which analyzed 40 monitoring wells using 25 hydrochemical parameters, was performed in the Lanyang Plain in 2004. Temperature, dissolved oxygen (DO), electrical potential (Eh), $\mathrm{pH}$ and electrical conductivity (EC) were measured in situ. The remaining water-quality items were measured in a laboratory. Eight hydrochemical items in the groundwater survey exceeded water-quality standards in different wells. These hydrochemical items are $\mathrm{EC}, \mathrm{Cl}^{-}, \mathrm{SO}_{4}^{2-}, \mathrm{NO}_{3}^{-}-\mathrm{N}$, $\mathrm{NH}_{4}^{+}-\mathrm{N}, \mathrm{Fe}, \mathrm{Mn}$ and As. Other metals included $\mathrm{Pb}, \mathrm{Cd}, \mathrm{Cr}$, $\mathrm{Cu}$ and $\mathrm{Zn}$, which were not analyzed in this study because these ion concentrations do not exceed standards or are not on the standard list. Additionally, several task-oriented surveys of groundwater quality, which focused on likely polluted wells, were performed during 2000-2003. Correlation analyses of each hydrochemical parameter measured among different years were used to assess temporal variations of hydrochemical quality. Correlation coefficients of more than 0.95 among measurements in different years were found in $\mathrm{EC}, \mathrm{Cl}^{-}, \mathrm{SO}_{4}^{2-}$, $\mathrm{Fe}, \mathrm{Mn}$ and $\mathrm{As}$, revealing that they may originate from natural seawater intrusion or geological sediment and have less temporal variations. Whereas, correlation coefficients of about 0.8 among measurements in different years were found in $\mathrm{NO}_{3}^{-}-\mathrm{N}$ and $\mathrm{NH}_{4}^{+}-\mathrm{N}$ with higher temporal variations. Furthermore, only $10 \%$ sewerage system has been constructed in Lanyang plain. Domestic waste water can easily infiltrate and pollute groundwater. The nitrogen pollution is a typical case resulting from human activities.

The field sampling methods used follow the NIEA code W103.50B set by the Taiwan Environment Protection Agency. At least 3 wellbore volumes of groundwater were pumped $b$ before sampling. Water samples for metal and other ion concentration measurements were filtered with $0.45 \mu \mathrm{m}$ glass fiber papers and acidified with $\mathrm{HNO}_{3}$ (Merck ultrapure grade) to $\mathrm{pH}$ 2. The $\mathrm{NO}_{3}^{-}-\mathrm{N}$ and $\mathrm{NH}_{4}^{+}-\mathrm{N}$ were determined by spectrophotometric techniques and $\mathrm{SO}_{4}^{2-}$ was determined by turbidimetric methods (APHA, 1998). Trace metal ions were measured by atomic absorption spectroscopy (AAS). A total of 15 samples including blank, spike, duplicate and check samples (standard solutions from Merck) were measured sequentially (APHA, 1998). The detection limits were $0.05,0.05$ and $0.1 \mathrm{mg} / \mathrm{L}$ for $\mathrm{Fe}, \mathrm{Mn}$ and As, respectively. Variances of duplicate measurements were less than $3 \%$; recoveries of check and spike samples were between $90 \%$ and $110 \%$.

Table 1 lists the maximums, medians and minimums of selected hydrochemical parameters in groundwater and their corresponding water-quality standards for different uses in Taiwan. For each hydrochemical parameter, the strictest value among the three water-quality standards, that is, the minimum value was selected for assessing multiple-purpose groundwater uses. Table 1 also lists the number of wells below the standard for each parameter. The lowest and highest numbers of wells exceeding the standard are zero for $\mathrm{NO}_{3}^{-}-\mathrm{N}$ and 28 for $\mathrm{NH}_{4}^{+}-\mathrm{N}$, respectively. Table 2 lists the number of wells exceeding the standards of each parameter in three aquifers. The highest number of wells exceeding the standards for irrigation is 5 for EC in aquifer 2 and $\mathrm{Mn}$ in aquifer 1 . The highest number of wells exceeding the criteria for aquaculture and the standards for drinking water supply is 13 for $\mathrm{Mn}$ in aquifer 1 . To simplify assessment of

Table 1 Statistics of hydrochemical parameters in groundwater and standards of water-quality for irrigation, aquaculture and drinking water

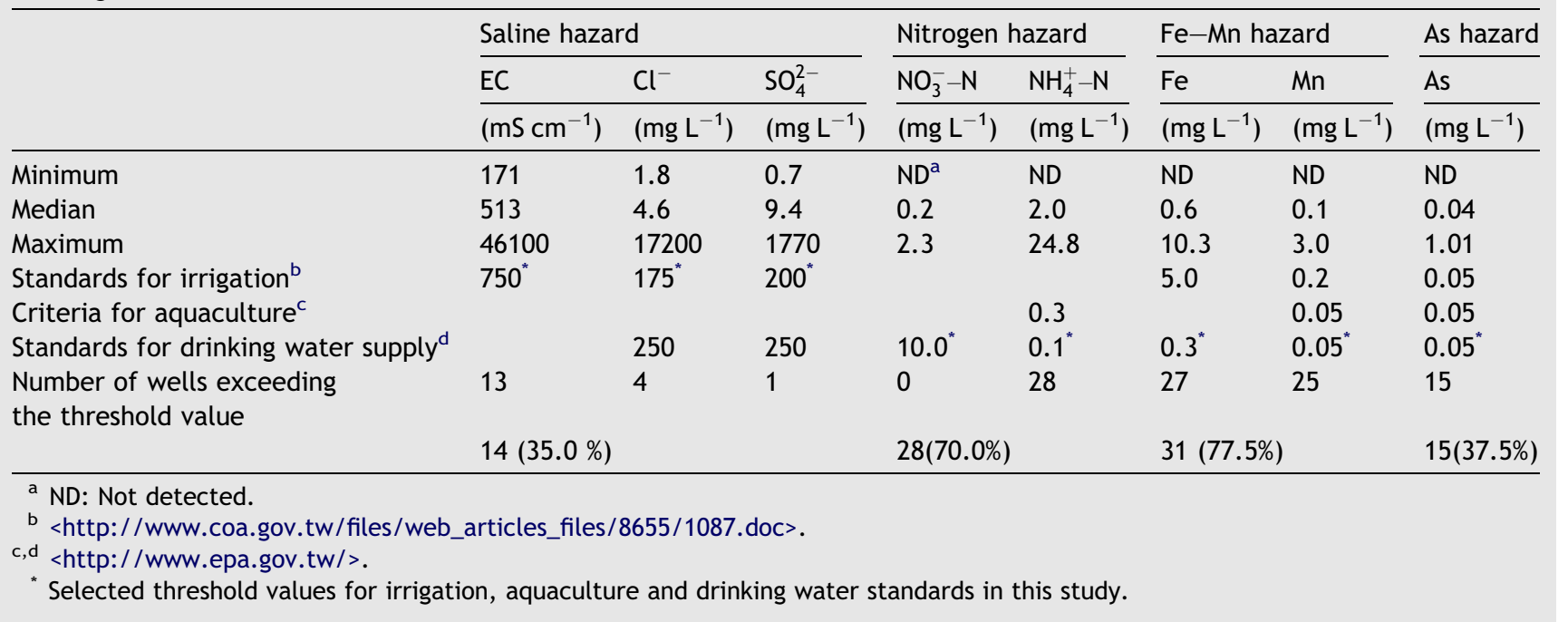


Table 2 Number of wells exceeding the standards of each parameter in three aquifers

\begin{tabular}{|c|c|c|c|c|c|c|c|c|}
\hline & \multicolumn{3}{|c|}{ Saline hazard } & \multicolumn{2}{|c|}{ Nitrogen hazard } & \multicolumn{2}{|c|}{ Fe-Mn hazard } & \multirow{2}{*}{$\frac{\text { As hazard }}{\text { As }}$} \\
\hline & $\overline{E C}$ & $\mathrm{Cl}^{-}$ & $\mathrm{SO}_{4}^{2-}$ & $\mathrm{NO}_{3}^{-}-\mathrm{N}$ & $\mathrm{NH}_{4}^{+}-\mathrm{N}$ & $\mathrm{Fe}$ & $\overline{M n}$ & \\
\hline \multicolumn{9}{|c|}{ Standards for irrigation } \\
\hline Aquifer 1 & 4 & 2 & 1 & - & - & 1 & 5 & 2 \\
\hline Aquifer 2 & 5 & 2 & 0 & - & - & 1 & 3 & 3 \\
\hline Aquifer 3 & 4 & 0 & 0 & - & - & 2 & 1 & 3 \\
\hline \multicolumn{9}{|c|}{ Criteria for aquaculture } \\
\hline Aquifer 1 & - & - & - & - & 12 & - & 13 & 2 \\
\hline Aquifer 2 & - & - & - & - & 9 & - & 6 & 3 \\
\hline Aquifer 3 & - & - & - & - & 7 & - & 6 & 3 \\
\hline \multicolumn{9}{|c|}{ Standards for drinking water supply } \\
\hline Aquifer 1 & - & 2 & 1 & 0 & 12 & 12 & 13 & 2 \\
\hline Aquifer 2 & - & 1 & 0 & 0 & 9 & 7 & 6 & 3 \\
\hline Aquifer 3 & - & 0 & 0 & 0 & 7 & 7 & 6 & 3 \\
\hline
\end{tabular}

hydrochemical parameters for irrigation, four hazards were applied to measure the water quality - saline hazard (EC, $\mathrm{Cl}^{-}$and $\mathrm{SO}_{4}^{2-}$ ), nitrogen hazard $\mathrm{NO}_{3}^{-}-\mathrm{N}$ and $\mathrm{NH}_{4}^{+}-\mathrm{N}$, and $\mathrm{Fe}-\mathrm{Mn}$ hazard (Fe and $\mathrm{Mn}$ ), and As hazard.

\section{Geostatistical approaches}

\section{Variogram analysis}

A geostatistical approach is based on the regionalized variable theory, and states that variables have both random and spatial structures in a given area. A variogram of the data should first be determined first. An experimental variogram is computed to quantify the spatial variability of variables. The experimental variogram is fitted by a theoretical model, $\gamma(h)$, which can be spherical, exponential or Gaussian model. Three parameters of the fitted model - nugget effect, sill and range - are determined. Variograms can be computed in different directions to detect any anisotropy in spatial variability. An anisotropic model generally includes geometric anisotropy and zonal anisotropy. Geometric anisotropy produces variograms that have the same structural shape and variability (sill + nugget) and a direction-dependent range for the spatial correlation. Additionally, the zonal anisotropy is defined by sills varying in direction (Deutsch, 2002).

In the study area, the spatial scale in the horizontal direction differs significantly from that in the vertical direction: the minimum distance between pairs of groundwater monitoring wells in the horizontal direction exceeds $2 \mathrm{~km}$, whereas the largest distance between two measurements of hydrochemical parameter concentrations in the vertical direction is less than $0.25 \mathrm{~km}$. This work thus used a three-dimensional (3D) spatial pairing strategy for determining experimental variograms in well screens with the same elevation at different stations (Type I), in wells with different elevations at different stations (Type II), and in different wells at the same station (Type III). Fig. 3 presents a conceptual diagram for the 3D spatial pairing strategy. The first two types, Types I and II whose maximum angles between pair vectors and the horizontal plane are under $7^{\circ}$, are defined as a horizontal and large-scale searching pair. The third type (Type III) is defined as a vertical and small-scale search pair. The zonal anisotropy, vertical variability, is perpendicular to geometric anisotropy, the horizontal variability. The variability is individually calculated from different pair types. Thus, vertical variability does not contribute to the horizontal variability with geometric anisotropy. When the analysis of the zonal anisotropy and geometric anisotropy is performed in a 3D space, variability at the three principal axes is independent. A nugget effect is the common variability for the nested variogram structure. Deutsch (2002) analyzed in detail the 3D anisotropic variability that was expressed as the vertical zonal variability on small-scale and the horizontal geometric variability on large-scale.

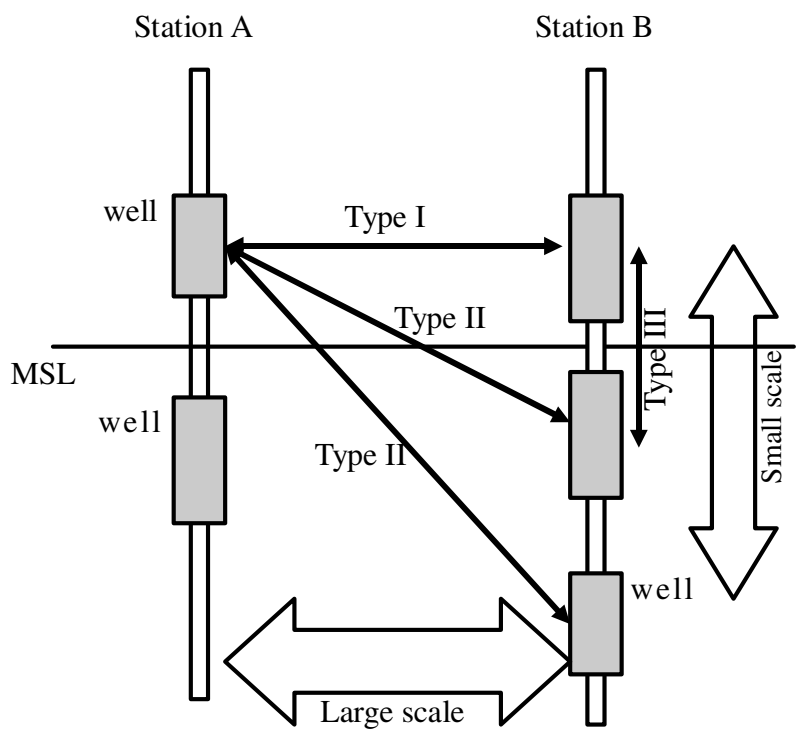

Figure 3 Conceptual diagram for three search pairs for determining experimental variograms. 


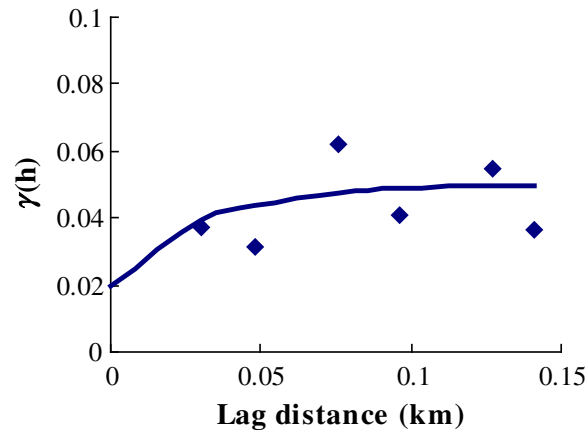

Vertical

(a) Saline hazard

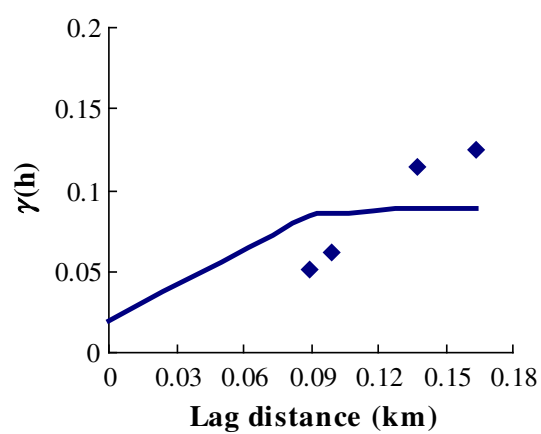

Vertical

(b) Nitrogen hazard

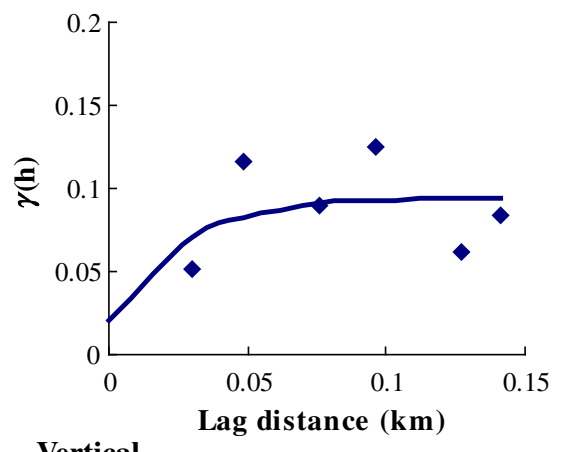

Vertical

(c) Fe-Mn hazard

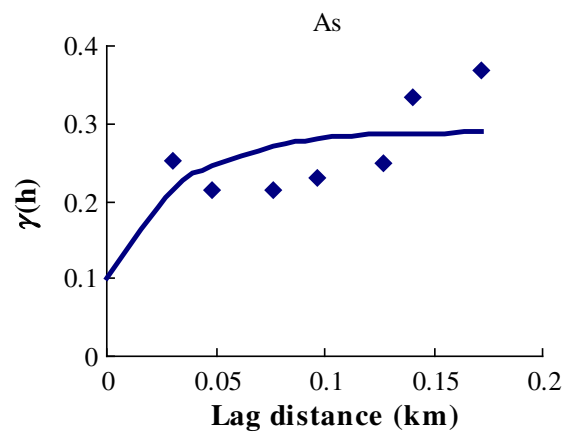

Vertical

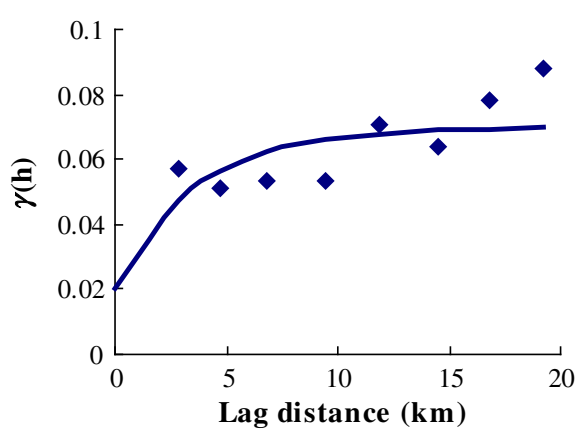

Horizontal

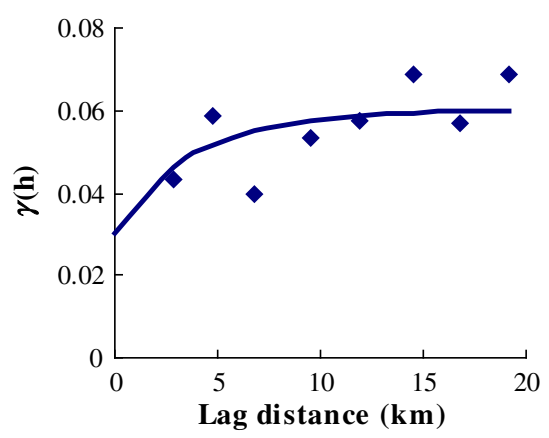

Horizontal

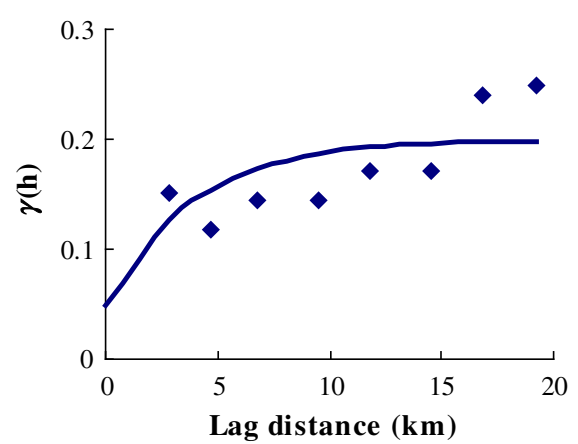

Horizontal

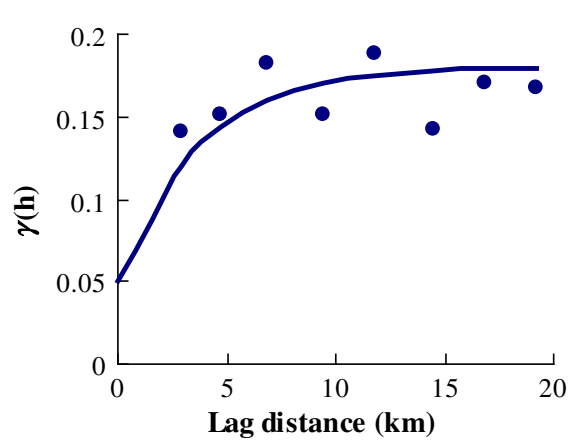

Horizontal

(d) As hazard

Figure 4 Experimental and theoretical variograms for multiple-variable integration of the four proposed hazards. 


\section{Multiple-variable indicator kriging}

Indicator kriging is a non-parametric geostatistical method for estimating the probability that an attribute value does not exceed a specific threshold, $z_{k}$, at a given location $u$ Goovaerts (1997). In IK, spatial variable $Z(u)$ is transformed into an indicator variable with a binary distribution as follows:

$I_{k}\left(\mathbf{u} ; \mathbf{z}_{k}\right)= \begin{cases}1, & \text { if } Z(\mathbf{u}) \leq \mathbf{z}_{k} \\ 0, & \text { otherwise }\end{cases}$

For MVIK, the multiple-variable integration is obtained by averaging indicator variables of several hydrochemical parameters and defined as follows (Diodato and Ceccarelli, 2004):

$I\left(\mathbf{u} ; \mathbf{z}_{p}\right)=\frac{1}{m} \sum_{k=1}^{m} I_{k}\left(\mathbf{u} ; \mathbf{z}_{k}\right)$

where $z_{p}$ is the threshold value of water-quality for multiple-purpose and the $m$ is the number of averaged indicator variables.

The expected value of $I\left(u ; z_{p}\right)$, which is conditional on $n$ surrounding data, can be expressed as

$E\left[I\left(\mathbf{u} ; \mathbf{z}_{p} \mid(n)\right)\right]=\operatorname{prob}\left\{Z(\mathbf{u}) \leq \mathbf{z}_{p} \mid(n)\right\}=F\left(\mathbf{u} ; \mathbf{z}_{p} \mid(n)\right)$

$P\left(\mathbf{u} ; z_{p} \mid(n)\right)=1-F\left(\mathbf{u} ; z_{p} \mid(n)\right)$

where $F\left(u ; z_{p} \mid(n)\right)$ is the conditional cumulative distribution function of $Z\left(u \leqslant z_{p}\right)$, and $P\left(\mathbf{u} ; z_{p} \mid(n)\right)$ is the probability that $Z(u)>z_{p}$. Indicator kriging is an estimation technique based on an estimator defined as

$I^{*}\left(\mathbf{u}_{0} ; \mathbf{z}_{p}\right)=\sum_{j=1}^{n} \lambda_{j}\left(\mathbf{z}_{p}\right) I\left(\mathbf{u}_{j} ; \mathbf{z}_{p}\right)$

where $I\left(\mathbf{u}_{j} ; z_{p}\right)$ represents the values of the indicator at the measured locations, $\mathbf{u}_{j}, j=1,2, \ldots, n$, and $\lambda_{j}$ is a weighting factor of $I\left(u_{j} ; z_{p}\right)$ used in estimating $I^{*}\left(u_{0} ; z_{p}\right)$ This work uses the gamv and kt3d codes in GSLIB (Deutsch and Journel, 1998) to perform the experimental variogram and IK, respectively.

\section{Results and discussion}

\section{Multiple-variable integration}

In this study, the saline hazard comprises three hydrochemical components; the nitrogen hazard, which contains two hydrochemical components; the Fe-Mn hazard, which has two hydrochemical components; and the As hazard, which has one hydrochemical component. Thus, the $m$ values in Eq. (2) are 3, 2, 2 and 1 for the saline hazard, nitrogen hazard, Fe-Mn hazard and As hazard, respectively. The analytical results reveal that 14, 28, 31 and 15 wells exceeded the threshold values for the saline hazard, nitrogen hazard, Fe$\mathrm{Mn}$ hazard and As hazard, respectively (Table 1). The Fe, Mn and $\mathrm{NH}_{4}^{+}-\mathrm{N}$ are the most critical hazards when assessing groundwater quality for multi-purpose use.

\section{Variogram analysis of multiple-variable integration}

A lag of $10 \mathrm{~m}$ was used to analyze the small-scale vertical variograms of multiple-variable integration of the four hazards. An exponential model yields the best fit for vertical variograms (the left graphs in Fig. 4) and the function is expressed as (Goovaerts (1997)):

$\gamma(h)=c_{0}=c\left[1-\exp \left(\frac{-3 h}{a}\right)\right]$

where $\gamma(h)$ is the variogram model, $c_{0}$ is the nugget effect, $c$ is the sill, and $a$ is the range. The nugget effect of a nested variogram is mainly inferred from a vertical variogram which typically has excellent spatial resolution. The fitted ranges, nugget effects and sills are $80-100 \mathrm{~m}, 0.02-0.1$ and $0.03-0.19$ (Table 3), respectively. A lag of $2400 \mathrm{~m}$ was then applied to analyze the horizontal omnidirectional variograms of the integration of the four hazards. To analyze zonal anisotropy, the fitted model of horizontal variograms should be consistent with the exponential model used in the vertical variograms (Deutsch, 2002) (right graphs in Fig. 4). The fitted ranges and sills are 11,000-12,000 m and $0.03-0.15$ (Table 3), respectively.

\section{Delineation of hazardous regions for multi-purpose water use}

When defining hazardous regions for irrigation, a probability threshold is inevitably subjective and depends on political and social policies (Goovaerts, 1997; Saisana et al., 2004). This work adopted $P\left(\mathbf{u} ; z_{p} \mid(n)\right)$ of $\leq 0.25,0.5$ and 0.75 to define hazardous regions for irrigation. Furthermore, these hazardous regions were divided into nine classifications: Fe-Mn (FM) hazard; nitrogen (N) hazard; As (As) hazard;

Table 3 Variograms and fitted parameters of multiple-variable integration of the four hazards. Exponential model was adopted to fit the experimental variograms

\begin{tabular}{lllll}
\hline Hazard type & Direction & Nugget & Sill & Range $(\mathrm{m})$ \\
\hline Saline hazard & $\mathrm{V}^{\mathrm{a}}$ & 0.02 & 0.03 & 90 \\
& $\mathrm{H}^{\mathrm{b}}$ & & 0.05 & 11000 \\
Nitrogen hazard & $\mathrm{V}$ & 0.02 & 0.07 & 80 \\
& $\mathrm{H}$ & & 0.03 & 11000 \\
Fe-Mn hazard & $\mathrm{V}$ & 0.02 & 0.075 & 80 \\
As hazard & $\mathrm{H}$ & 0.1 & 0.15 & 12000 \\
& $\mathrm{~V}$ & & 0.19 & 100 \\
\hline
\end{tabular}

\footnotetext{
${ }^{\text {a }}$ V: Vertical.

b $\mathrm{H}$ : Horizon.
} 
combined $\mathrm{Fe}-\mathrm{Mn}$ and nitrogen $(\mathrm{FM}+\mathrm{N})$ hazards; combined $\mathrm{Fe}-\mathrm{Mn}$ and $\mathrm{As}(\mathrm{FM}+\mathrm{As})$ hazards; combined Fe-Mn and saline $(F M+S)$ hazards; combined $F e-M n$, nitrogen and saline $(\mathrm{FM}+\mathrm{N}+\mathrm{S})$ hazards; combined $\mathrm{Fe}-\mathrm{Mn}$, nitrogen and As $(F M+N+A s)$ hazards; and combined $F e-M n$, saline, nitrogen and As (FM+ S + N + As) hazards.

Fig. 5 shows the safe regions (in white) and hazardous regions defined using the nine classifications for multi-purpose water use based on $P\left(\mathbf{u} ; \mathbf{z}_{p} \mid(n)\right) \leq 0.75$. High hazards regions have poor water-quality for multi-purpose use. Table 4 presents the proportions of hazardous areas to total area covered by the nine classifications. Roughly, $37 \%$ of the study area is classified as hazardous. The area of safe groundwater for multi-purpose use is in the proximal-fan, central distalfan and mid-fan, and partial northern distal-fan aquifers. The FM hazard accounts for main hazardous area, which is distributed in the southern and northern aquifers; and has the highest proportion, approximately $39.7 \%$ of the study area among the classifications. Other hazards, such as the

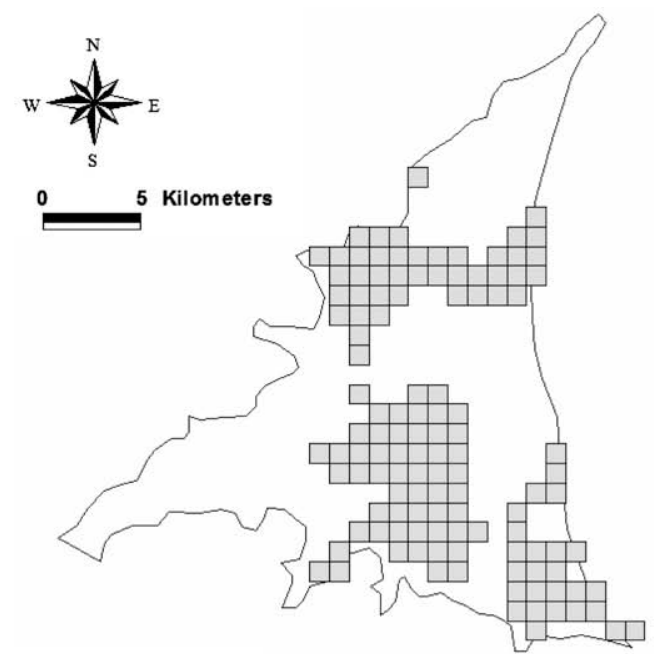

(a) aquifer 1

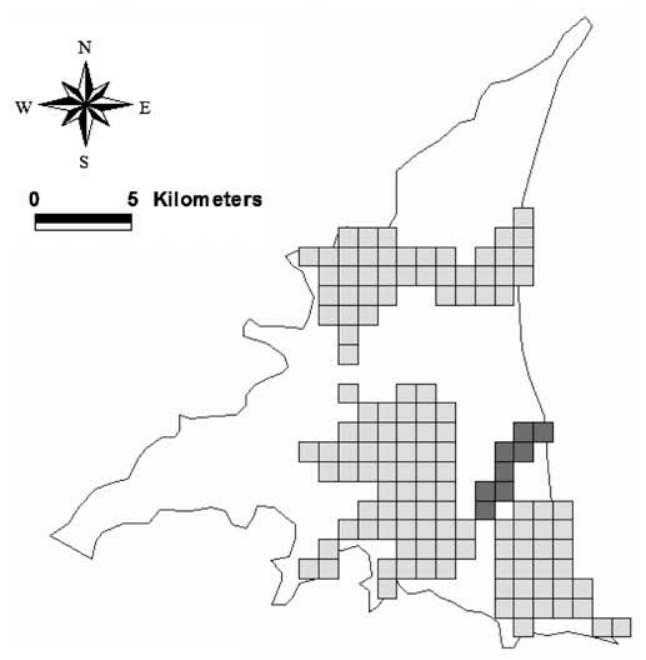

(c) aquifer 3
As hazard, the area is distributed in southern coastal aquifers, and principally present in aquifers 2 and 3. The area of the As hazard is $0-2.4 \%$ of the study area.

Fig. 6 displays the safe and hazardous regions based on the nine classifications for irrigation using the $P\left(\mathbf{u} ; z_{p} \mid(n)\right) \leq 0.5$. About $73.1 \%$ of the study area is classified as hazardous regions (Table 3 ). Areas with safe groundwater for multi-purpose use are in the proximal-fan, partial central distal-fan, and northern distal-fan aquifers. The area of FM hazard, which is slightly decreased in the northern aquifers, accounts for $27.2-31.1 \%$ of the study area. The area of $\mathrm{FM}+\mathrm{N}$ hazard, which generally occurs in the northern mid-fan and distal-fan, and southern coastal aquifers, covers about $33.6 \%$ of the study area. The area of FM+As hazard is near the As hazard, which is distributed in the southern coastal aquifers, covering approximately 4.7$5.3 \%$ of the study area. The area of FM $+\mathrm{S}$ hazard accounts for about $2.3 \%$ of the study area, and is distributed in the northern coastal aquifers. The area of $\mathrm{N}$ hazard covers

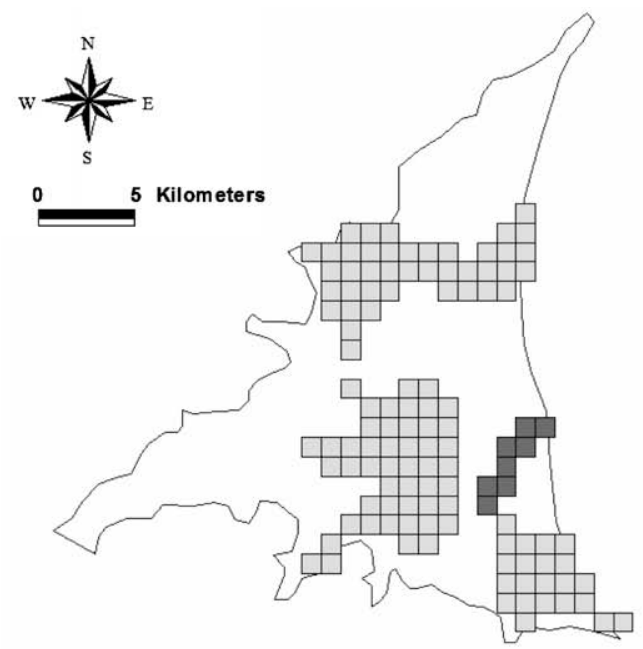

(b) aquifer 2

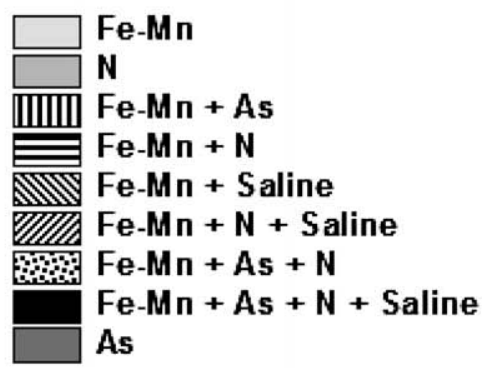

Figure 5 Delineation of hazardous regions for the nine classifications for $P\left(\mathbf{u} ; \mathbf{z}_{p} \mid(n)\right) \geq 0.75 \mathrm{Fe}-\mathrm{Mn}$ is the Fe-Mn hazard; $\mathrm{N}$ is the nitrogen hazard; As is the As hazard; saline is the saline hazard. 
Table 4 Proportions (\%) of hazardous areas to total areas of the three aquifers based on the nine hazard classifications

\begin{tabular}{|c|c|c|c|c|}
\hline Hazards & Aquifer 1 & Aquifer 2 & Aquifer 3 & Average \\
\hline \multicolumn{5}{|c|}{$P\left(u ; z_{p} \mid(n)\right) \geqslant 0.75$} \\
\hline$F M^{a}$ & 36.1 & 32.8 & 37.3 & 35.4 \\
\hline $\mathrm{N}^{\mathrm{b}}$ & 0.0 & 0.0 & 0.0 & 0.0 \\
\hline$F M+A s^{c}$ & 0.0 & 0.0 & 0.0 & 0.0 \\
\hline $\mathrm{FM}+\mathrm{N}$ & 0.0 & 0.0 & 0.0 & 0.0 \\
\hline$F M+S^{d}$ & 0.0 & 0.0 & 0.0 & 0.0 \\
\hline $\mathrm{FM}+\mathrm{N}+\mathrm{S}$ & 0.0 & 0.0 & 0.0 & 0.0 \\
\hline$F M+N+A s$ & 0.0 & 0.0 & 0.0 & 0.0 \\
\hline$F M+N+S+A s$ & 0.0 & 0.0 & 0.0 & 0.0 \\
\hline As & 0.0 & 2.4 & 2.4 & 1.6 \\
\hline Total & 36.1 & 35.2 & 39.7 & 37.0 \\
\hline \multicolumn{5}{|c|}{$P\left(u ; z_{p} \mid(n)\right) \geqslant 0.5$} \\
\hline $\mathrm{FM}$ & 29.3 & 27.2 & 31.1 & 29.2 \\
\hline$N$ & 1.0 & 1.0 & 1.0 & 1.0 \\
\hline$F M+A s$ & 4.7 & 5.3 & 4.7 & 4.9 \\
\hline$F M+N$ & 33.4 & 33.7 & 33.7 & 33.6 \\
\hline$F M+S$ & 1.5 & 2.7 & 2.7 & 2.3 \\
\hline $\mathrm{FM}+\mathrm{N}+\mathrm{S}$ & 0.3 & 0.2 & 0.2 & 0.2 \\
\hline$F M+N+A s$ & 0.0 & 0.0 & 0.0 & 0.0 \\
\hline$F M+N+S+A s$ & 0.0 & 0.0 & 0.0 & 0.0 \\
\hline As & 0.3 & 2.7 & 2.7 & 1.9 \\
\hline Total & 70.4 & 72.8 & 76.1 & 73.1 \\
\hline \multicolumn{5}{|c|}{$P\left(u ; z_{p} \mid(n)\right) \geqslant 0.25$} \\
\hline $\mathrm{FM}$ & 19.2 & 17.8 & 17.2 & 18.1 \\
\hline $\mathrm{N}$ & 5.0 & 5.0 & 8.9 & 6.3 \\
\hline$F M+A s$ & 2.1 & 3.6 & 2.7 & 2.8 \\
\hline$F M+N$ & 20.7 & 20.1 & 23.1 & 21.3 \\
\hline$F M+S$ & 6.2 & 6.2 & 6.2 & 6.2 \\
\hline $\mathrm{FM}+\mathrm{N}+\mathrm{S}$ & 12.4 & 13.6 & 13.6 & 13.2 \\
\hline$F M+N+A s$ & 17.5 & 15.1 & 13.6 & 15.4 \\
\hline$F M+N+S+A s$ & 11.8 & 13.6 & 13.6 & 13.0 \\
\hline As & 0.0 & 0.0 & 0.0 & 0.0 \\
\hline Total & 94.9 & 95.0 & 98.9 & 96.3 \\
\hline
\end{tabular}

${ }^{a}$ FM: heavy metal hazard.

${ }^{b} \mathrm{~N}$ : nitrogen hazard.

c As: arsenic hazard.

d S: saline hazard.

about $1 \%$ of the study area, and is distributed near the northeastern mountains.

Fig. 7 reveals the safe regions and hazardous regions based on the nine classifications for multi-purpose water use via the stringent criteria of $P\left(\mathbf{u} ; z_{p} \mid(n)\right) \leq 0.25$. Approximately, $96.3 \%$ of the study area is classified as hazardous. The area with safe groundwater for multi-purpose use is in the partial proximal-fan aquifers. The areas of the FM, $\mathrm{FM}+\mathrm{As}$, and $F M+N$ hazards are decreased. The $\mathrm{N}$, $\mathrm{FM}+\mathrm{N}+\mathrm{S}, \mathrm{FM}+\mathrm{N}+\mathrm{As}$, and $\mathrm{FM}+\mathrm{N}+\mathrm{S}+$ As hazards is considerable in size in the study area. The area of the $F M+N+S$ hazard is distributed in the northern mid-fan and distal-fan aquifers, accounting for roughly $13.2 \%$ of the study area and is near the area with $F M+S$ hazard. The area of the $\mathrm{FM}+\mathrm{N}+$ As hazard is distributed primarily in the central mid-fan and the southern coastal distal-fan aquifers, covering approximately $13.6-17.5 \%$ of the study area. The area of the $\mathrm{FM}+\mathrm{N}+\mathrm{S}+$ As hazard is distributed in the southern distal-fan aquifers, covering about $13 \%$ of the study area. The area of the $\mathrm{N}$ hazard is distributed in the proximal-fan aquifers, accounting for approximately $5-8.9 \%$ of the study area.

\section{Zonal management of multi-purpose groundwater use}

Regions with safe groundwater vary with the selected probability threshold. Fig. 8 presents the distribution of safe groundwater for MVIK critical probabilities of $\geqslant 0.75,0.5$ and 0.25 . Delineation of multi-purpose safe use of groundwater based on the MVIK probability of $\geqslant 0.5$ was adopted. The proximal-fan, partial central distal-fan and northern distal-fan aquifers are the optimal zones for extracting groundwater for multi-purpose uses according to the MVIK 


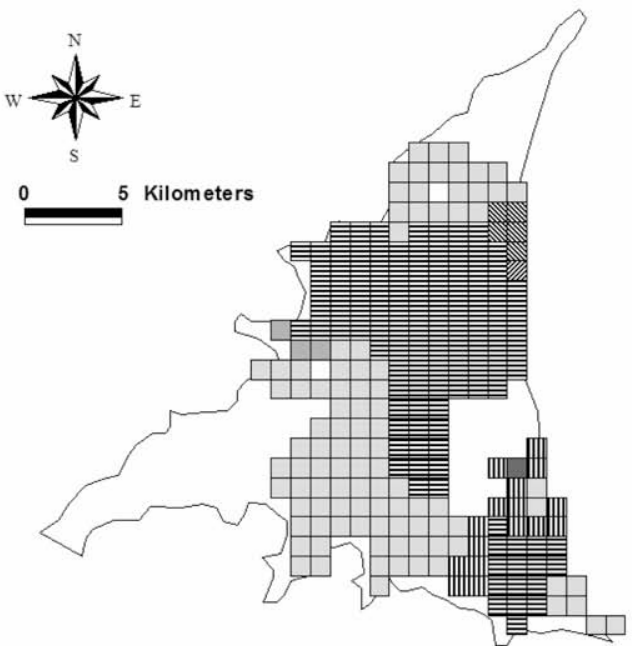

(a) aquifer 1

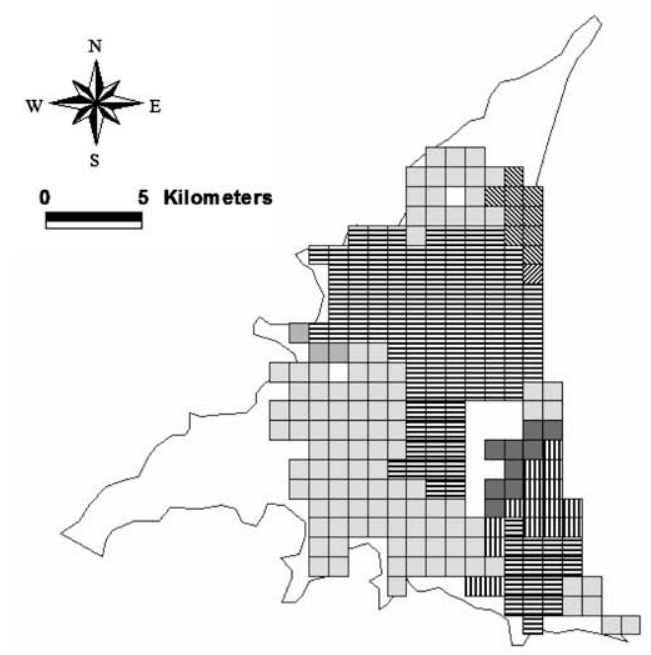

(c) aquifer 3

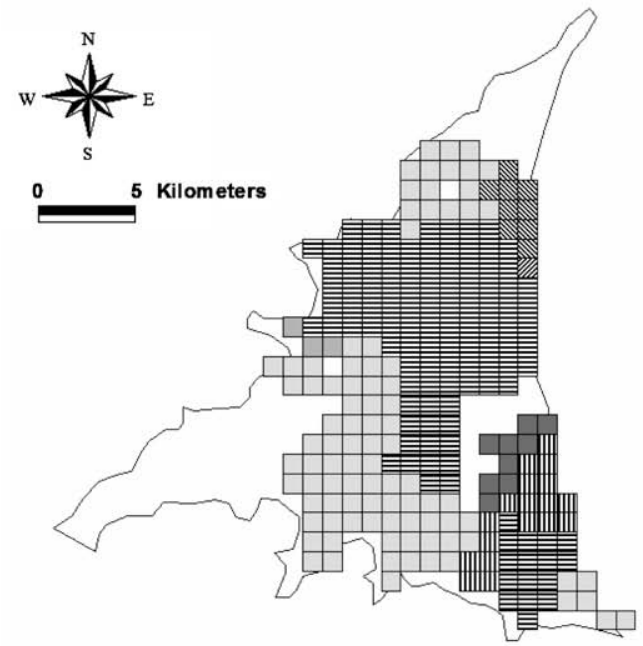

(b) aquifer 2

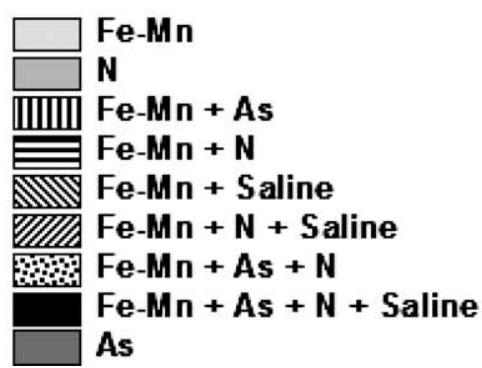

Figure 6 Delineation of hazardous regions for the nine classifications for $P\left(\mathbf{u} ; \mathrm{z}_{p} \mid(n)\right) \geq 0.5 \mathrm{Fe}-\mathrm{Mn}$ is the Fe-Mn hazard; $\mathrm{N}$ is the nitrogen hazard; As is the As hazard; saline is the saline hazard.

assessment. Notably, the deep aquifer has high hazard ratings and is less safe for use than the shallow aquifer. Moreover, the FM hazard in groundwater of the Lanyang Plain presents in most of the area, which also partially overlaps with other hazards, such the $\mathrm{N}$ and As hazards, thereby, forming various hazard types. Thus, zonal management strategies for groundwater use should comply with the measured groundwater quality for region and land use types. According to the water rights, roughly 57 million $\mathrm{m}^{3}$ of groundwater is extracted annually in this study area (<http://wuss.wra.gov.tw/annmisc.asp >). The annual demand for groundwater by agriculture, aquaculture, households and for tap water are 10.5, 4, 4.5 and 38 million $\mathrm{m}^{3}$, respectively. However, a massive amount of groundwater was extracted from many illegal wells, especially for household, agriculture and aquaculture uses. The government has adopted a control measure to avoid over-pumping groundwater and prevent land subsidence in the Lanyang Plain.
The restricted regions are Tou-Chen, Jiao-Si, Yuna-Shan, Jhung-Wei, Wu-Jie, Don-Shan and Su-Ao (<http:// www.lsprc.ncku.edu.tw/subsideqa/section.htm>).

For aquaculture, the $\mathrm{FM}$ and $\mathrm{FM}+\mathrm{N}$ hazards exist in the northern region, Jioa-Si and costal region; however, these hazards have minimal toxic effect and can be tolerated. The area of the three hazards-FM, FM+N, and FM+N+As hazards-are present in the southern region. Don-Shan is a main fish farming area, growth of farmed fish can cause bioaccumulation of heavy metal, particularly As, thereby posing a potential threat to human health via food chain ingestion. Arsenic hazard in aquifers mainly causes by the mobilization of As from iron-rich sediment to groundwater in reducing conditions (Lee et al., 2008). One option to minimize hazard is to relocate fish ponds to the west, or to San-Shin. The cost-benefit and transport of aquacultural products, change of land uses, and the willingness of fishers to move should be handled properly. If the aquacultural 


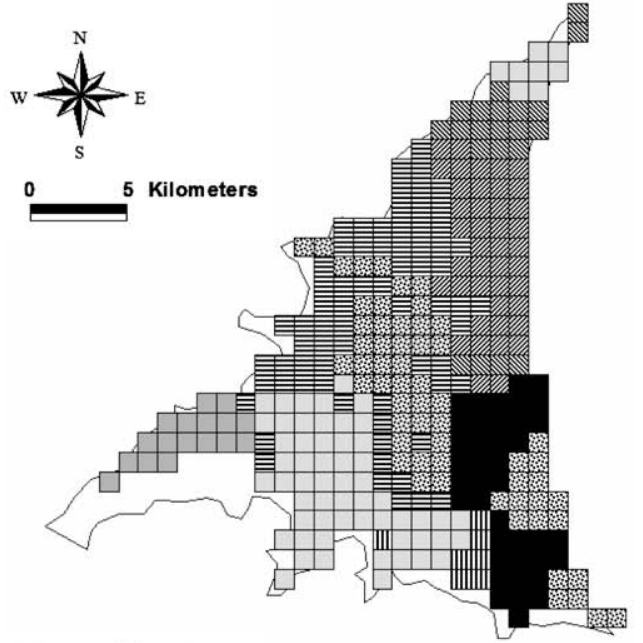

(a) aquifer 1
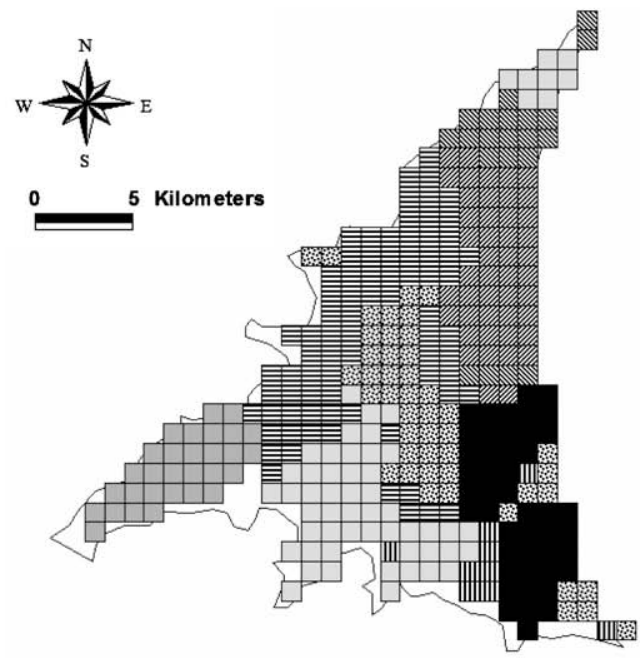

(c) aquifer 3

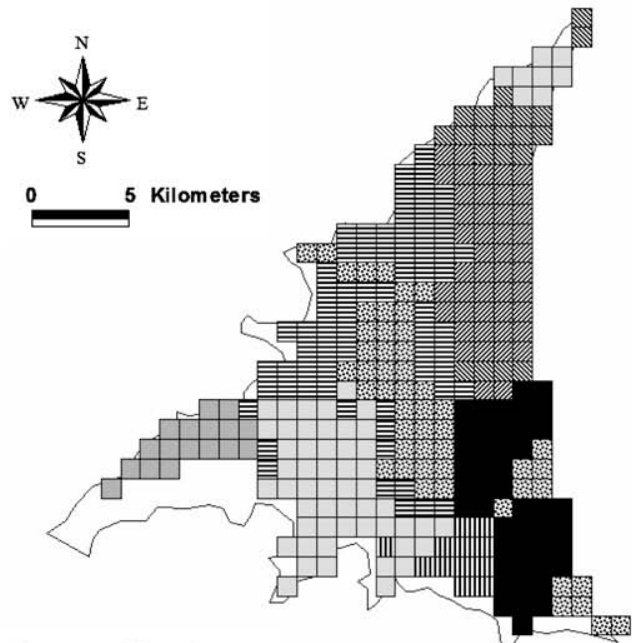

(b) aquifer 2

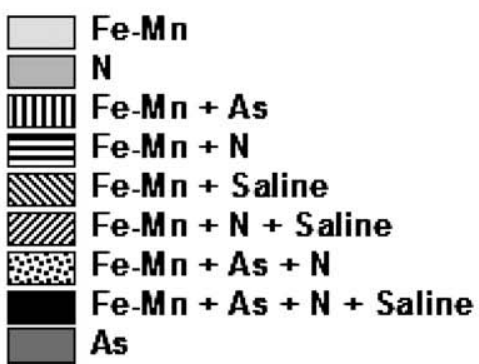

Figure 7 Delineation of hazardous regions for the nine classifications for $P\left(\mathbf{u} ; \mathbf{z}_{p} \mid(n)\right) \geq 0.25 \mathrm{Fe}-\mathrm{Mn}$ is the $\mathrm{Fe}-\mathrm{Mn}$ hazard; $\mathrm{N}$ is the nitrogen hazard; As is the As hazard; saline is the saline hazard.

ponds are not relocated, groundwater for use should be pretreated, such as diluted by surface water, filtration, or a relatively stricter probability threshold value should be introduced to protect human health. Notably, groundwater salinization distributed at northern distal-fan area was mainly caused by infiltration of semi-saline fishpond water, which mixed with groundwater and seawater for farming (Peng, 1995). Replacement of coastal fishpond farming by offshore sea farming can resolve the local ground water salinization problem.

Agriculture is distributed in most regions of the Lanyang Plain, and groundwater is a inexpensive and easily accessed by farmers. For crops that require massive amounts of water to grow, such as rice, should not be planted in regions with the combined As with other hazard or the As hazard alone. These As hazardous regions can be planted with upland crops, such as wheat or sweet potatoes. Additionally, a feasible strategy can be utilized that uses different criteria for the probability threshold value for hazards based on local irrigation demand.

The FM, N and As hazards are present in residential wells. Notably, ingesting As in groundwater poses a health hazard (Chiou et al., 2001; Lee et al., 2007). Ingesting groundwater is not recommended to ingest except in safe regions, particularly in the northern mid- and distal-fan, and the southern costal region. The government should adopt measures to reduce hazards, such as reducing the amount of groundwater extracted or changing groundwater uses. Some wells overseen by TWC in hazard regions; thus, extracted groundwater should be used or potential hazards reduced, such as $\mathrm{Fe}, \mathrm{Mn}, \mathrm{N}$ and As, via water treatment processes (Meng et al., 2001; Choo et al., 2005; Gupta et al., 2005; Tyrovola et al., 2006; Tekerlekopoulou and Vayenas, 2007) before being supplied to households. A feasible measure is to decrease the amount of groundwater extracted in hazardous regions, and increases that extracted in safe regions. 


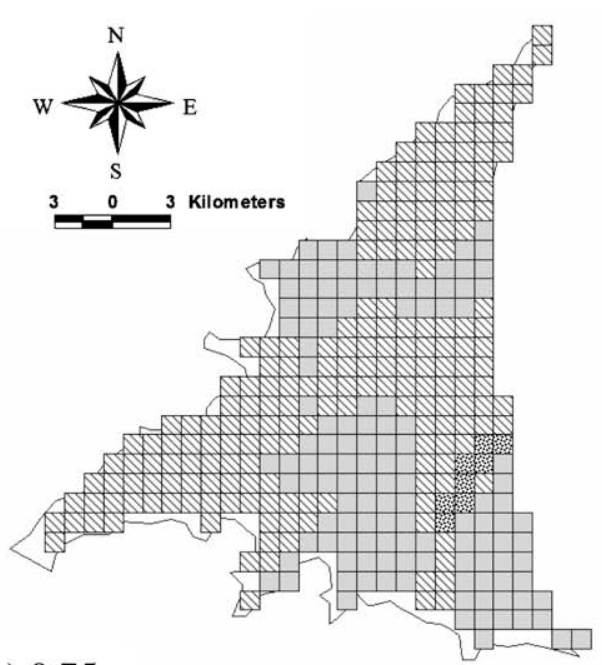

(a) 0.75

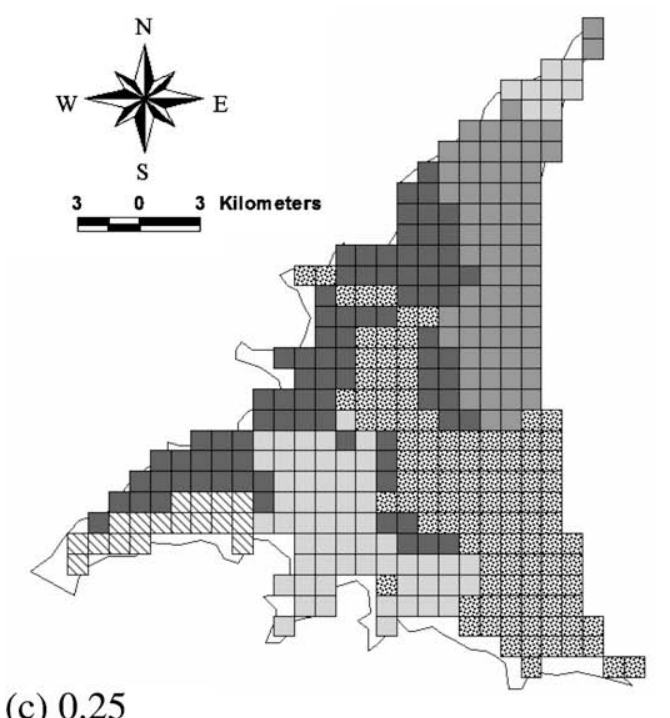

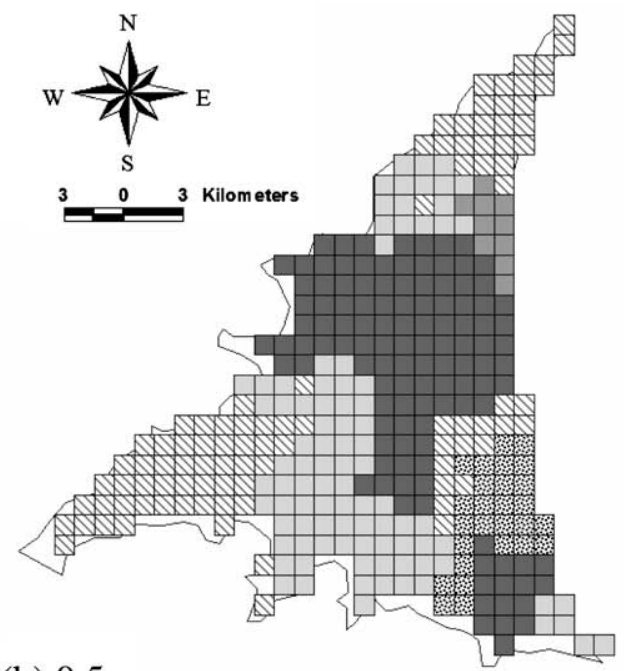

(b) 0.5

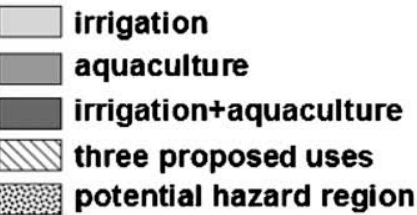

Figure 8 Zonal distribution of safe groundwater different uses based on the MVIK critical probabilities of $\geqslant 0.75,0.5$ and 0.25 .

However, a complex tap supply system and re-deployment of water resources must to be retrofitted.

\section{Conclusion}

This work analyzed the water-quality of groundwater resources for multi-purpose use in the Lanyang Plain. Multiple-variable indicator kriging was adopted to assess numerous hydrochemical parameters for water-quality standards for irrigation, aquaculture and drinking water in Taiwan. Several hydrochemical parameters were simplified and classified using the saline, N, As and FM hazards. Area with safe and potentially hazardous groundwater for multi-purpose uses were identified according to estimated probabilities using MVIK. The demarcation of the hazardous regions under various probabilities facilitates an exploration of spatial uncertainty of assessed parameters and the establishment of a robust policy associated with the development of groundwater resources. Analytical results suggest that the proximal-fan, partial central distal-fan and northern distal-fan aquifers are optimal regions for groundwater extraction and use for all three purposes of irrigation, aquaculture and drinking. Notably, the deep aquifer has high hazards and is less safe for various uses than the shallow aquifer. The mid-fan and distal-fan aquifers have poor water-quality due to the presence of multiple hazards. Although the proximal-fan aquifer is a primary zone of groundwater recharge, groundwater with $\mathrm{N}$ can decrease the water-quality when the groundwater is used for irrigation or drinking water. The FM hazard in groundwater is present in most of the Lanyang Plain, and is also partially combined with other hazards, such $\mathrm{N}$ and As hazard, thereby forming various hazard types. Thus, zonal management strategies based on the MVIK delineation of hazardous regions is proposed for multi-purpose safe use of groundwater in the Lanyang Plain. Analytical results are useful to local governments when developing safe use of multi-purpose groundwater resources in similar regions. 


\section{Acknowledgements}

The authors would like to thank the Water Resources Agency of the Ministry of Economic Affairs, Republic of China, for providing data. This work is supported by the National Science Council of ROC under Contract No. NSC 096-2628-B002-021-MY3.

\section{References}

APHA, 1998. Standard Methods for the Examination of Water and Water Waste, 20th ed. American Public Health Association, Washington, DC, pp. 413-426.

Castrignanò, A., Goovaerts, P., Lulli, L., Bragato, G., 2000. A geostatistical approach to estimate probability of occurrence of Tuber melanosporum in relation to some soil properties. Geoderma 98, 95-113.

Chen, W.S., 2000. Analysis of sediments and sedimentary environments in stratigraphic correlation of the lanyang plain. Report to the Central Geological Survey Report, Ministry of Economic, Taiwan, ROC.

Chiou, H.Y., Chiou, S.T., Hsu, Y.H., Chou, Y.L., Tseng, C.H., Wei, M.L., Chen, C.J., 2001. Incidence of transitional cell carcinoma and arsenic in drinking water: a follow-up study of 8120 residents in an arseniasis-endemic area in northeastern Taiwan. American Journal of Epidemiology 153, 411-418.

Choo, K.H., Lee, H., Choi, S.J., 2005. Iron and manganese removal and membrane fouling during UF in conjunction with prechlorination for drinking water. Journal of Membrane Science 267, $18-26$.

Deutsch, C.V., 2002. Geostatistical Reservoir Modeling. Oxford University Press, New York, pp. 124-152.

Deutsch, C.V., Journel, A.G., 1998. GSLIB: Geostatistical Software Library and User's Guide, 2nd ed. Oxford University Press, New York.

Diodato, N., Ceccarelli, M., 2004. Multivariate indicator kriging approach using a GIS to classify soil degradation for Mediterranean agricultural lands. Ecological Indicators 4 (3), 177-187.

Frías-Espericueta, M.G., Voltolina, D., Osuna-LóPez, I., 2003. Acute toxicity of copper, zinc, iron, and manganese-manganese to white leg shrimp Litopenaeus vannamei Postlarvae. Bulletin of Environmental Contamination and Toxicology 71, 68-74.

Goovaerts, P., 1997. Geostatistics for Natural Resources Evaluation. Oxford University Press, New York, pp. 259-368.

Goovaerts, P., AvRuskin, G., Meliker, J., Slotnick, M., Jacquez, G., Nriagu, J., 2005. Geostatistical modeling of the spatial variability of arsenic in groundwater of southeast Michigan. Water Resources Research 41. doi:10.1029/2004WR003705.

Grieve, C.M., Poss, J.A., Amrhein, C., 2006. Response of Matthiola incana to irrigation with saline wastewaters. Hortscience 41 (1), $119-123$.

Gupta, V.K., Saini, V.K., Jain, N., 2005. Adsorption of As(III) from aqueous solution by iron oxide-coated sand. Journal of Colloid and Interface Science 288, 55-60.

Halvorson, J.J., Smith, J.L., Papendick, R.I., 1996. Integration of multiple soil parameters to evaluate soil quality: a field example. Biology and Fertility of Soils 21 (3), 207-214.

Huq, S.M.I., Naidu, R., 2005. Arsenic in groundwater and contamination of the food chain: Bangladesh scenario. Natural arsenic in groundwater occurrence, remediation and management. In: Proceedings of the 32nd International Geological Congress, Florence, Italy, pp. 95-101.

Jang, C.S., Liu, C.W., Lin, K.H., Huang, F.M., Wang, S.W., 2006. Spatial analysis of potential carcinogenic risks associated with ingesting arsenic in aquacultural tilapia (Oreochromis mossambicus) in blackfoot disease hyperendemic areas. Environmental Science and Technology 40, 1707-1713.

Juang, K.W., Lee, D.Y., 1998. Simple indicator kriging for estimating the probability of incorrectly delineating hazardous areas in a contaminated site. Environmental Science and Technology 32, 2487-2493.

Jurdi, M., Korfali, S.I., Karahagopian, Y., Davies, B.E., 2002. Evaluation of water quality of the Qaraaoun reservoir, Lebanon: suitability for multipurpose usage. Environmental Monitoring and Assessment 77, 11-30.

Karaivazoglou, N.A., Papakosta, D.K., Divanidis, S., 2005. Effect of chloride in irrigation water and form of nitrogen fertilizer on Virginia (flue-cured) tobacco. Field Crops Research 92 (1), 6174.

Lake, I.R., Lovett, A.A., Hiscock, K.M., Betson, M., Foley, A., Sünnenberg, G., Evers, S., Fletcher, S., 2003. Evaluating factors influencing groundwater vulnerability to nitrate pollution: developing the potential of GIS. Journal of Environmental Management 68, 315-328.

Lee, J.J., Jang, C.S., Wang, S.W., Liu, C.W., 2007. Evaluation of potential health risk of arsenic-affected groundwater using indicator kriging and dose-response model. The Science of Total Environment 384, 151-162.

Lee, J.J., Jang, C.S., Wang, S.W., Liang, C.P., Liu, C.W., 2008. Delineation of spatial redox zones using discriminant analysis and geochemical modeling in arsenic-affected alluvial aquifers. Hydrological Processes 21 (16), 3029-3041.

Liu, C.W., Jang, C.S., Liao, C.M., 2004. Evaluation of arsenic contamination potential using indicator kriging in the Yun-Lin aquifer (Taiwan). The Science of the Total Environment 321, 173-188.

Liu, C.W., Huang, F.M., Hsueh, Y.M., 2005. Revised cancer risk assessment of inorganic arsenic upon consumption of tilapia (Oreochromis mossambicus) from blackfoot disease hyperendemic area. Bulletin of Environmental Contamination and Toxicology 74, 1037-1044.

Màrquez, M., Vodopivez, C., Casaux, R., Curtosi, A., 1998. Metal $(\mathrm{Fe}, \mathrm{Zn}, \mathrm{Mn}$ and $\mathrm{Cu}$ ) levels in the Antarctic fish Notothenia coriiceps. Polar Biology 20, 404-408.

Meng, X., Korfiatis, G.P., Christodoulators, C., Bang, S., 2001. Treatment of arsenic in Bangladesh well water using a household co-precipitation and filtration system. Water Research 35, 2805-2810.

Oyedele, D.J., Amusan, A.A., Obi, A.O., 1996. The use of multiplevariable indicator kriging technique for assessment of the suitability of an acid soil for maize. Tropical Agriculture 73 (4), 259-263.

Peng, T.R., 1995. Environmental isotopic study on meteroric water and groundwater in I-Lan area. Doctoral Dissertation, Institute of Geology, National Taiwan University, Taiwan.

Saisana, M., Dubois, G., Chaloulakou, A., Spyrellis, N., 2004. Classification criteria and probability risk maps: limitations and perspectives. Environmental Science and Technology 38, 12751281.

Smith, J.L., Halvorson, J.J., Papendick, R.I., 1993. Using multiplevariable indicator kriging for evaluating soil quality. Soil Science Society of America Journal 57, 743-749.

Tekerlekopoulou, A.G., Vayenas, D.V., 2007. Ammonia, iron and manganese removal from potable water using trickling filters. Desalination 210, 225-235.

Tyrovola, K., Nikolaidis, N.P., Veranis, N., Kallithrakas-Kontos, N., Koulouridakis, P.E., 2006. Arsenic removal from geothermal waters with zero-valent iron-Effect of temperature, phosphate and nitrate. Water Research 40, 2375-2386.

van Meirvenne, M., Goovaerts, P., 2001. Evaluating the probability of exceeding a site-specific soil cadmium contamination threshold. Geoderma 102, 75-100. 
van der Vorm, P.D.J., van Diest, A., 1979. Aspect of the Fe and $\mathrm{Mn}$ nutrition of rice plants. Plant and Soil 52, 19-29.

Xu, Y., Chen, Y.X., Wang, J.S., Liu, Q.M., 2006. Using indicator kriging to analyze and evaluate spatial distributions of soil water and salt in field. Advances in Water Science 17, 477-482.
Yang, C.Y., Cheng, M.F., Tsai, S.S., Hsieh, Y.L., 1998. Calcium, magnesium, and nitrate in drinking water and gastric cancer mortality. Japanese Journal of Cancer Research 89, 124-130. 